\title{
SEGMENTAL SPECIALIZATION OF A LEECH SWIM-INITIATING INTERNEURON, CELL 205
}

\author{
JANIS C. WEEKS ${ }^{2}$ \\ Department of Biology, University of California, San Diego, La Jolla, California 92093
}

Received December 2, 1981; Revised February 5, 1982; Accepted February 5, 1982

\begin{abstract}
The physiological and anatomical properties of an unpaired intersegmental interneuron designated cell 205 are described. Cell 205 is unusual among leech neurons in that it combines a variety of functional properties in a single cell. Constant current depolarization of cell 205 initiates and maintains swimming behavior in semi-intact leeches or the swim motor pattern in brainless, isolated nerve cords. During swim episodes elicited by other stimuli, cell 205 is rhythmically active. Current pulses passed into cell 205 during swimming reset the pattern, indicating that it has access to, or may be a member of, the swim central pattern generator (CPG). Cell 205 is the first interneuron in this system to exhibit both swim-initiating and CPG functions. Individual touch, pressure, and nociceptive primary mechanoreceptor neurons polysynaptically excite cell 205 , which, in addition, is coupled electrically to the multimodal $\mathrm{S}$ interneuron. These inputs may contribute to the initiation and/or modulation of swimming in response to sensory stimuli. Cell 205 shares some common synaptic inputs and outputs with the only other known swim-initiating interneuron, cell 204, but the two cells differ fundamentally in that cell 204 exerts only a tonic effect on the CPG. No synaptic interactions were found between cells 204 and 205, but their excitatory effects on swimming summate. Unlike other swim neurons which are segmentally repeated, cell 205 generally is present only in segment 9, and numerous lines of evidence suggest that it is, in fact, a segmentally differentiated homolog of cell 204.
\end{abstract}

Most, if not all, rhythmic behaviors of vertebrates and invertebrates are produced by central pattern generators (CPGs), but the most detailed knowledge of how central neurons generate cyclic output in the absence of sensory feedback has come from invertebrates (reviewed in Delcomyn, 1980; Kristan, 1980). This work has benefitted greatly by the identifiability of particular neurons as unique individuals in animal after animal. Using intracellular and extracellular electrophysiological recording techniques and anatomical methods, specific features of behavioral output can be attributed to the properties and synaptic connections of individual neurons.

\footnotetext{
'I thank William B. Kristan, Jr., in whose laboratory this work was carried out, for valuable suggestions and criticisms. I also thank Walter Stewart for providing Lucifer Yellow, B. L. Granzow for horseradish peroxidase fills, and R. L. Calabrese, W. O. Friesen, W. B. Kristan, J. Y. Kuwada, J. P. Miller, M. P. Nusbaum, and W. M. Roberts for criticizing earlier drafts of the manuscript. This research was supported by Public Health Service Predoctoral Traineeships 5T32GM07153-05 and ST01AI0453 (J. C. W.) and Public Health Service Grant NS14410 and National Science Foundation Grants BNS79-23459 and BN575-23567 (W. B. Kristan, Jr.).

${ }^{2}$ Present address: Department of Zoology, NJ-15, University of Washington, Seattle, WA 98195.
}

The leech has been a useful preparation for studying the neuronal basis of several behaviors, including swimming. During this behavior, leeches elongate, flatten, and undulate dorsoventrally. In each segment, the motor pattern consists of alternating contractions of dorsal and ventral longitudinal muscles, with the contraction cycles of individual segments coordinated metachronously such that undulatory waves travel posteriorly along the body. In minimally dissected preparations or totally isolated, brainless nerve cords, the swim motor pattern is recorded in ganglionic nerves as rhythmic impulse bursts in motor axons (Kristan et al., 1974a, b; Kristan and Calabrese, 1976).

Of the approximately 400 neurons comprising each segmental ganglion (Macagno, 1980), three classes of cells which participate in swimming have been identified: motor neurons, CPG interneurons, and swim-initiating interneurons. The motor neurons do not generate the rhythmic swim pattern themselves but have it imposed upon them by an interneuronal CPG. The first four CPG interneurons identified (cells 27, 28, 33, and 123, termed the "oscillator cells") were proposed to form an oscillatory network operating on the principle of recurrent cyclic inhibition (Kling and Szekely, 1968) based on 
electronic neuromimetic modeling of their synaptic connections (Friesen and Stent, 1977; Friesen et al., 1978; Poon et al., 1978). However, more recent experimental tests of this model (Weeks, 1981) have shown that the proposed circuit is incomplete and that other neurons must participate in pattern generation. In fact, other CPG cells have been described (Poon, 1976; Friesen et al., 1978; Weeks, 1980, 1982b) but not yet incorporated into the model.

Intracellular stimulation of CPG interneurons does not elicit swimming behavior; the only previously described cell to do so is the interneuron cell 204 (Weeks and Kristan, 1978). Although rhythmically active during swims, cell 204 is not a member of the CPG but instead exerts only a tonic excitatory effect on the pattern (Weeks, 1981). Cell 204 activation appears to be a normal mode of swim initiation in freely behaving animals (Weeks and Kristan, 1978; Weeks, 1982a, b).

This paper describes a newly identified interneuron, cell 205, which has both swim-initiating and patterngenerating properties and which may be a segmentally differentiated homolog of cell 204. The interactions of cell 205 with cell 204 , sensory neurons, a multimodal interneuron, a pattern-generating interneuron, and motor neurons also are described.

\section{Materials and Methods}

Experimental techniques. Leeches, Hirudo medicinalis, Macrobdella decora, and Macrobdella sestertia, were obtained from distributors and maintained in aquaria filled with $5 \%$ Instant Ocean (Aquarium Systems, Eastlake, $\mathrm{OH})$ in distilled water at $15^{\circ} \mathrm{C}$. The majority of the experiments ( 34 of 52 ) were performed on $H$. medicinalis, but, except where noted, similar results were obtained in all three species. Animals were fed on bullfrogs at least once every 3 months. Dissections and experiments were performed in leech physiological saline (Nicholls and Purves, 1970) as modified by Weeks (1981). On occasion, the $\mathrm{Mg}^{2+}$ concentration of the saline was raised to 2 to $5 \mathrm{~mm}$ (replacing an osmotically equivalent amount of $\mathrm{Na}^{+}$) to stop spontaneous muscle contractions in the nerve cord which interfere with intracellular recording. This treatment has no effect on the swim pattern (Friesen et al., 1978). Preparations were of three types: (1) semi-intact leeches, consisting of the complete animal with several ganglia exposed and immobilized and the connectives to the head and tail brains crushed (Kristan et al., 1974a); (2) brainless, isolated nerve cords, consisting of a chain of 19 of the 21 segmental ganglia (ganglia 2 to 20; Kristan and Calabrese, 1976); and (3) short chains of isolated ganglia. In some cases, a flap of body wall was left attached to the latter two preparations by segmental nerves to monitor muscle contractions and allow sensory stimulation. All experiments were done at 20 to $23^{\circ} \mathrm{C}$.

Segmental ganglia were numbered sequentially, beginning with the first ganglion posterior to the head brain (Kristan et al., 1974a). Segmental nerve branches were designated as described by Ort et al. (1974). Unpaired neurons were designated by number and ganglionic location (e.g., cell 205(9) denotes the cell 205 in ganglion 9 ). Bilaterally paired nerves were designated further as right or left (e.g., DP $(13, \mathrm{R})$ is the right dorsal branch of the posterior nerve of ganglion 13), but this designation was omitted sometimes when irrelevant. Teft and right segmental nerves of each ganglion exhibit essentially identical swim motor patterns (Kristan et al., 1974b). For brevity, the terms "swim motor pattern" and "swimming" will be used interchangeably.

The electrophysiological techniques for recording and stimulating neuronal activity were as described previously (Kristan et al., 1974a, b; Ort et al., 1974). Intracellular recordings were made using glass micropipettes filled with $3 \mathrm{M}$ potassium acetate (resistance, 30 to 60 megohms), while extracellular recordings were taken with suction electrodes. Amplified recordings were displayed simultaneously on a multiple trace storage oscilloscope and pen recorder and recorded at $7 \frac{1}{2}$ inches/sec on magnetic tape for later playback using a Vetter Crown model A recorder. Some neurons were filled with the dye Lucifer Yellow (Stewart, 1978) by iontophoresis from intracellular electrodes or were pressure-injected with horseradish peroxidase (HRP) and visualized using the general technique of Muller and Scott (1981).

Identification of cell 205. The physiological properties found to be most helpful in identifying cell 205 (see "Results") were (1) cell body size and location, (2) ability to drive swimming when depolarized, (3) action potential shape, (4) ability to drive "dorsal sustained" swims, (5) ventral burst phase during swimming, (6) ability to reset swimming, (7) polysynaptic input from touch, pressure, and nociceptive cells, $(8)$ rectifying electrical coupling to the $S$ cell, and (9) anatomy as revealed by dye fills. Among the neurons in the anteromedial cell packet, cell 205 was most likely to be confused with cell 204 , but properties 3, 4, and 6 to 9 serve to distinguish them. Generally, given a cell with properties 1 and 2, property 3 reliably distinguishes cells 204 and 205 because the former neuron has smaller (2- to $5-\mathrm{mV})$ single and "doublet" spikes (Weeks and Kristan, 1978; Weeks, 1981), whereas the latter has larger (5- to $12-\mathrm{mV}$ ) and exclusively single spikes.

\section{Results}

Morphology of cell 205. The cell 205 soma (diameter, approximately $25 \mu \mathrm{m}$ ) is located on the ventral ganglionic surface in the anteromedial cell packet and commonly lies immediately lateral or posterior to a Retzius cell. In the present study, intracellular recordings were made from 52 cells 205 in Hirudo and Macrobdella. Of these neurons, 16 were filled with Lucifer Yellow or HRP and all were found to have a characteristic structure (Fig. $1 A$ ) consisting of an extensive, bilaterally symmetric arborization with a single interganglionic axon entering the anterior unpaired connective, Faivre's nerve. This axon extends for at least 9 segments (Fig. $1 B$ ). The distribution of the intraganglionic processes of cell 205 is quite similar to two other swim interneurons: cell 204 (Weeks and Kristan, 1978) and cell 208 (Weeks, 1980, 1982b).

All previously studied swim motor neurons and interneurons recur throughout the nerve cord (Stuart, 1970; Ort et al., 1974; Friesen et al., 1978; Weeks, 1980, 1982b). In contrast, cell 205 generally is present only in ganglion 


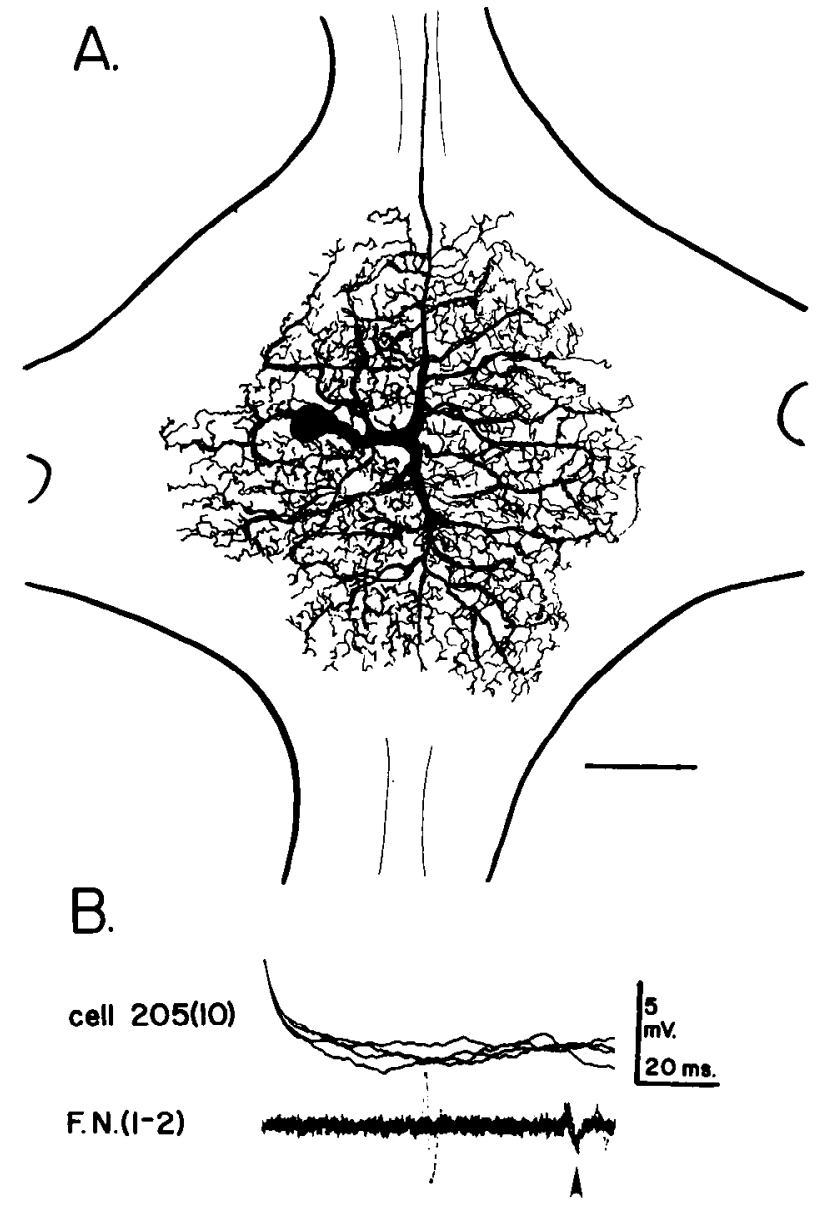

Figure 1. A, Camera lucida drawing of an HRP-filled cell 205 in ganglion 9 of $H$. medicinalis. The dye-filled neuron was kindly provided by B. L. Granzow (Department of Biology, University of California, San Diego). Anterior is up. Scale bar, $100 \mu \mathrm{m}$. $B$, Demonstration of cell 205 spikes in anterior Faivre's nerve. Shown are five superimposed oscilloscope sweeps triggered on intracellularly recorded cell $205(10)$ action potentials (upper trace) which match spikes (arrowhead) recorded extracellularly from the cut end of Faivre's nerve (FN) anterior to ganglion 2 (FN(1-2); lower trace). The preparation was a $M a$ crobdella isolated nerve cord. Cell 205(9) spikes were observed similarly in $\mathrm{FN}(1-2)$ in other preparations (not shown).

9 , where 50 of the 52 cells 205 were found. The remaining 2 cells were found in ganglia 8 and 10 (e.g., Fig. $1 B$ ), and in both preparations, a cell 205 was present in ganglion 9 as well. Rarely, cell 204 rather than cell 205 was found in ganglion 9. In spite of extensive searches, cell 204 and cell 205 were never found together in the same ganglion. Previously, it was suggested that every ganglion contains a cell 204 (Weeks and Kristan, 1978), but further studies have shown cell 204 to be present reliably in ganglia 10 to 16 , intermittently in ganglia 8 and 9 (never in ganglion 9 if cell 205 is present) and in ganglia posterior to 16 , and never in ganglion 7 or more anterior ganglia. Because the preponderance of recordings were made in ganglia 9 to 14 , the distribution of neurons of these ganglia is more certain than elsewhere. The possibility that cells 204 and 205 are more widely distributed than this but were missed during searches cannot be ruled out (e.g., they probably would have been missed had their cell bodies moved out of the anteromedial cell packet). However, other small interneurons, such as cell 208 and the $S$ cell, are found readily in this packet all along the nerve cord (Weeks, $1982 \mathrm{~b}$; data not shown).

Swim patterns eliciled by cell 205. Tonic firing in cell 205 driven by intracellularly injected depolarizing current elicits swimming behavior in semi-intact leeches or the swim motor pattern in isolated nerve cord preparations (Fig. 2A). The fundamental swim motor pattern consists of rhythmic, alternating bursts of spikes in motor neurons innervating dorsal and ventral longitudinal muscles (Ort et al., 1974); in Figure $2 A$, only dorsal phase bursts are shown. During the first swim bout in Figure $2 A$, the average values of cell 205 firing frequency and swim cycle period (the interval between dorsal burst midpoints) were about $50 \mathrm{~Hz}$ and $1.5 \mathrm{sec}$, respectively, whereas during the second bout, these values were $30 \mathrm{~Hz}$ and 1.8 sec. Thus, a higher cell 205 firing rate was associated with shorter swim cycle period, a relation observed for cell 204 as well (Weeks and Kristan, 1978).

The swim motor patterns shown in Figure $2 A$ are indistinguishable from those normally produced by isolated nerve cords or semi-intact leeches (e.g., Kristan et al., 1974b; Kristan and Calabrese, 1976; Weeks and Kristan, 1978). Sometimes, however, cell 205 also elicits a somewhat different swim pattern (Fig. $2 B$ ). In Figure $2 B 1$, cell 205 firing (about $40 \mathrm{~Hz}$ ) drove a pattern characterized by abnormally prolonged dorsal bursts with ventral activity of normal duration. During this pattern, the cycle period averaged $2.7 \mathrm{sec}$, whereas swim cycle periods normally never exceed 2 sec. (Kristan et al., 1974a, b; Kristan and Calabrese, 1976; Weeks, 1981). Figure $2 B 2$ shows another pattern sometimes elicited by cell 205 in which, after one normal cycle of dorsal and ventral alternation, dorsal activity persisted until cell 205 stimulation was stopped. For ease of reference, these will be called "dorsal sustained" swim motor patterns. All cells 205 tested were able to drive normal swims but only about $60 \%$ of them also produced dorsal sustained swims. This value is probably an underestimate, however, because not all cells were tested exhaustively for this ability.

Evidence that dorsal sustained patterns are a variant of the normal swim pattern came from observing semiintact leeches. When cell 205 stimulation elicited normal burst patterns, swimming behavior was normal, whereas during dorsal sustained patterns, swimming movements were arrested with the animal's anterior and midbody segments strongly flexed dorsally. During this time, the posterior body was either flexed ventrally or held in an intermediate position. Between prolonged dorsal flexions, ventral flexions were performed normally. Thus, during dorsal sustained patterns in segmental nerves, animals produced unmistakable swimming behavior except that dorsal flexions were held too long, thereby causing an increased swim cycle period. In semi-intact preparations in which cells 204 and 205 were penetrated simultaneously, swimming behavior elicited by stimulating cell 204 was invariably normal, whereas cell 205 produced either normal swims or swims with prolonged dorsal flexions.

One possible determinant of which type of swim pattern cell 205 stimulation evoked was cell 205's firing frequency. This was tested in 8 preparations by injecting varying levels of constant depolarizing current (up to 2 $\mathrm{nA}$ ) into cell 205. During 36 depolarizations which elicited 

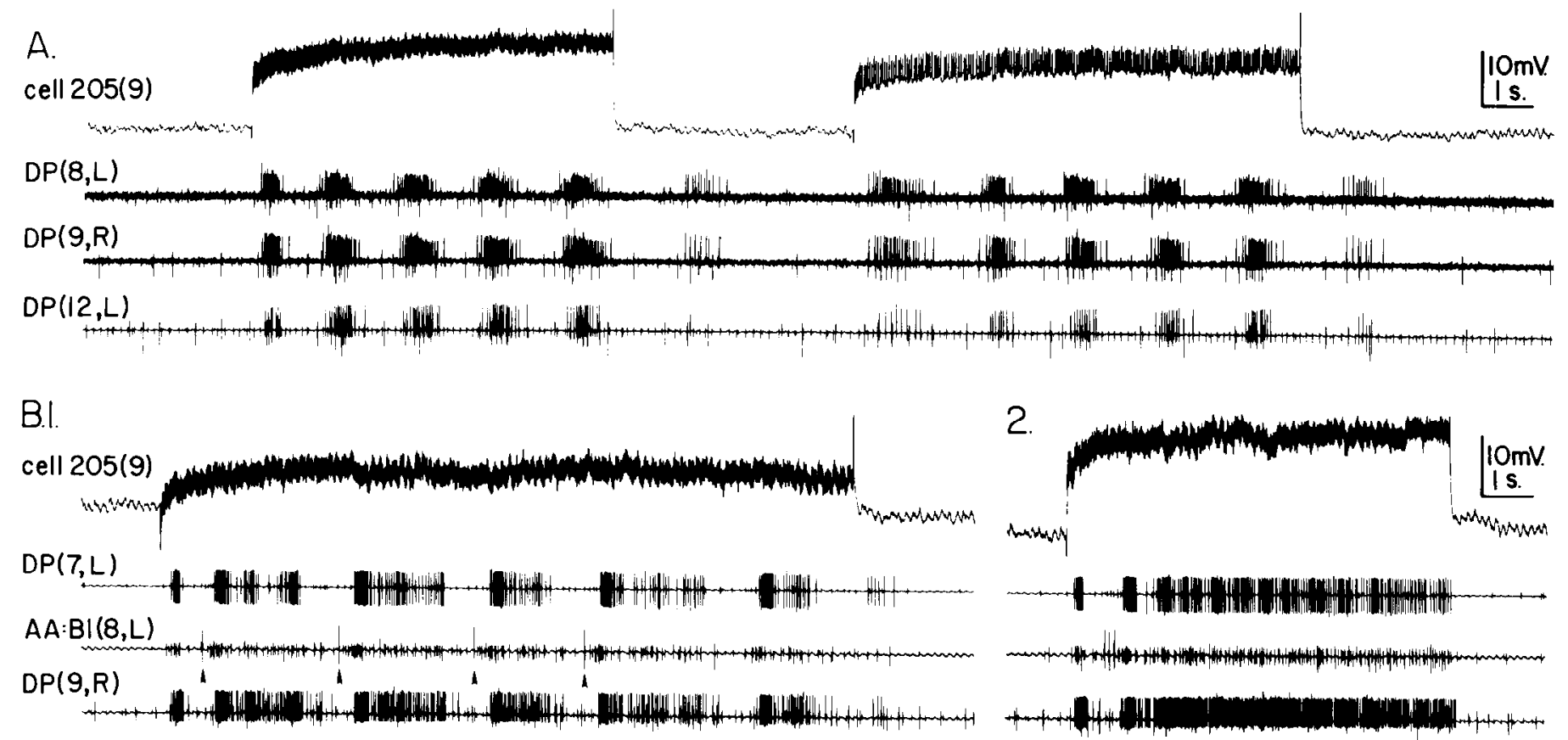

Figure 2. Normal $(A)$ and dorsal sustained $(B)$ swim motor patterns evoked by cell 205 . In each panel, the top trace is an intracellular recording from cell 205(9), while the lower traces are extracellular recordings from segmental nerves. The spike bursts in the DP (dorsal branch of the posterior nerve) recordings are those of cell 3, a dorsal excitor motor neuron (Ort et al., 1974). In the AA:B1 (first branch of the anterior branch of the anterior nerve) recordings, the large spikes are those of cell 108, a ventromedial excitor, while the small spikes are dorsal units (Ort et al., 1974). Cell 108's spikes are marked by arrowheads in B1. Parenthesized numbers and letters denote the recording location; e.g., DP $(8, \mathrm{~L})$ is the left DP nerve of the 8th segmental ganglion. In each panel, tonic cell 205 activity was elicited by intracellularly injected depolarizing current. The preparations in $A$ and $B$ were different Hirudo isolated nerve cords.

normal swim bouts, cell 205's mean firing rate was $46 \pm$ 21 (SD) $\mathrm{Hz}$ (range, 11 to $82 \mathrm{~Hz}$ ). During 33 other depolarizations in which cell 205 drove dorsal sustained swims, its mean firing rate was the same or $46 \pm 22 \mathrm{~Hz}$ (range, 9 to $88 \mathrm{~Hz}$ ). This independence of the cell 205 firing frequency and swim pattern type held for individual cells as well as for the pooled data. These results indicate that some property not under experimental control determined which pattern would be elicited by cell 205 stimulation.

Cell 205 has access to the central pattern generator. Two necessary properties for a neuron to be considered part of a rhythmic CPG are: (1) the cell must be cyclically active in phase with the motor pattern and (2) brief currents injected into the cell can phase-shift (reset) an ongoing motor pattern (Friesen et al., 1978). In accordance with the first property, cell 205 fires ventral phase impulse bursts during swimming (Fig. $3 A$ ), but the degree to which its activity is cyclic varies both between bouts and within bouts (e.g., compare Figs. 3, 5, 6, and 7) in all types of preparation used. Cell 205's firing rate was measured during 28 swims elicited by transient DP nerve stimulation in 6 preparations. Mean impulse frequency during the initial cycle of each swim was $24 \pm 9 \mathrm{~Hz}$, and the mean for entire swim bouts was $13 \pm 5 \mathrm{~Hz}$. These frequencies are within the range of those which, when driven by injected current, drive swimming (see above).

That cell 205 can reset the swim pattern was shown by injecting brief current pulses ( 4 to $10 \mathrm{nA}$ ) during swim episodes (Fig. $3 B$ ). These currents are in the same range as those which elicit resetting in other leech CPG interneurons (Friesen et al., 1978; Weeks, 1982b; data not shown). During the first current pulse in Figure $3 B$, the swim pattern was arrested in dorsal phase, with tonic dorsal activity in all segmental nerves. A second current pulse again arrested the pattern and terminated the swim. To obtain resetting reliably, currents much larger than those adequate to elicit swimming (less than $2 \mathrm{nA}$ ) were required. Still, not every cell 205 tested produced resetting, but this is also true of other leech CPG cells (W. O. Friesen, personal communication; Weeks, 1982a, b). Hyperpolarization of cell 205 did not affect the swim pattern. In semi-intact leeches, segmental nerve burst resetting produced by brief cell 205 depolarization is accompanied by a temporary arrest of swim undulations in the dorsally flexed posture described above.

Cell 205's ability to reset the pattern is characteristic of a CPG function, but the observed variability in its rhythmicity during swims suggests that its burst pattern is not critical for cycle-by-cycle timing of the swim rhythm under the circumstances tested. In contrast, the oscillator cells and cell 208 fire distinct bursts throughout swim episodes (Friesen et al., 1978; Weeks, 1982a, b). Strictly speaking, therefore, cell 205 cannot presently be considered a member of the pattern-generating circuit, but it clearly has access to the CPG and can strongly influence the phasing of CPG output.

Sensory pathways to cell 205. Leeches often respond to touch by initiating swimming (Kristan and Calabrese, 1976; Kristan et al., 1982). Consistent with its role as a swim initiator, cell 205 is excited by either light touch or pressure applied to the body wall of its own segment (Fig. $4 A$ ). Mechanosensory excitation of cell 205 is well accounted for hy activation of identified primary sensory 

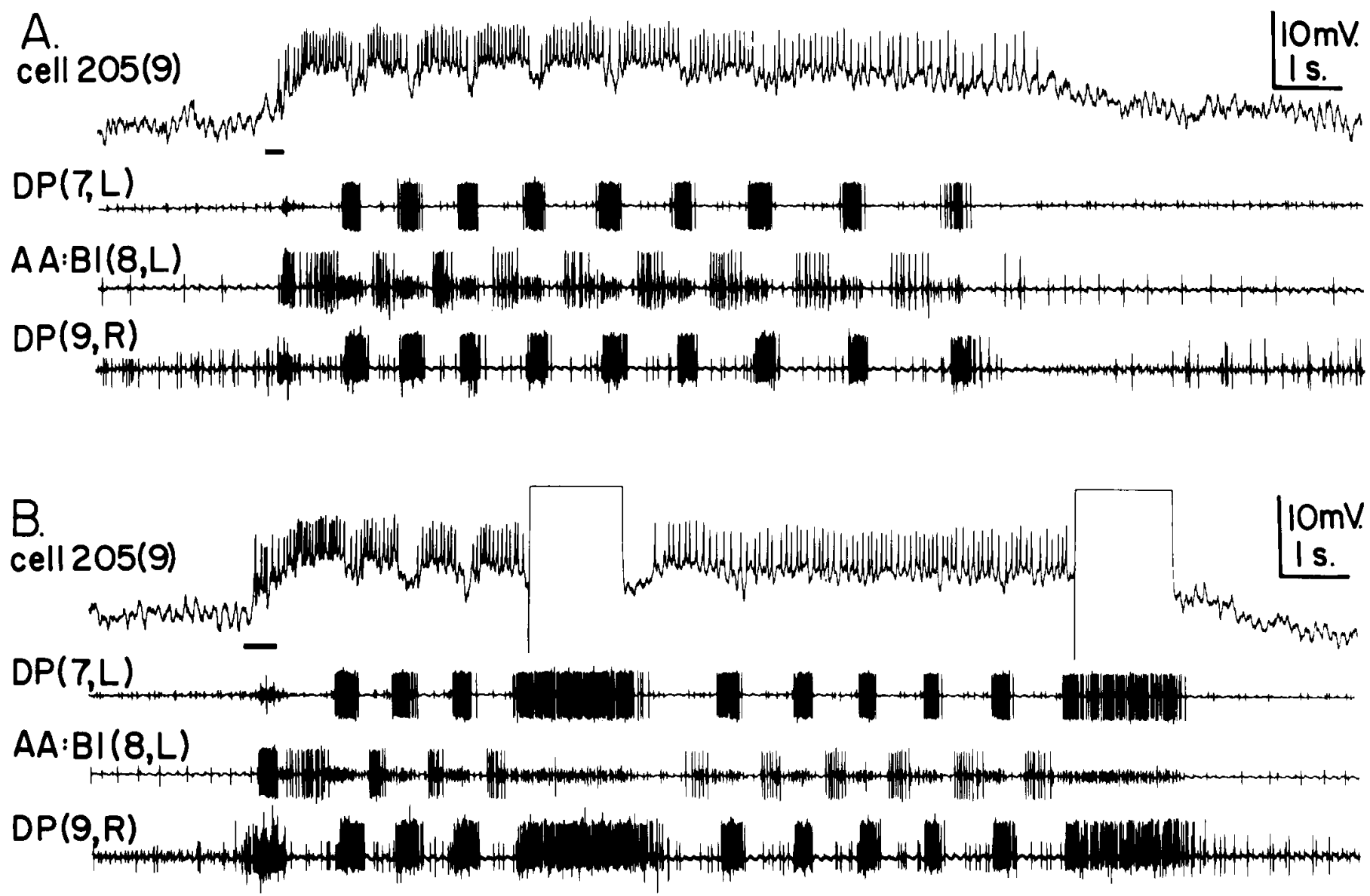

Figure 3. Swim activity pattern $(A)$ and resetting capability $(B)$ of cell 205 . In both panels, the upper trace is intracellular, while the lower traces are extracellular recordings. DP nerves show dorsal bursts, while AA:B1 nerves show dorsal and ventral bursts. Swim episodes were elicited by transient electrical stimulation (bar) of DP(14, R) (not shown). Cell 205 's firing frequency during the 2 swims was roughly $15 \mathrm{~Hz}$. During the upward deflections of the cell 205(9) trace in $B$, an approximately 4-nA depolarizing current was injected into the cell. The preparation was a Hirudo isolated nerve cord.

neurons (Fig. $4 B$ ); for instance, cell 205's responses to body wall pressure and intracellular stimulation of a $\mathrm{P}$ (pressure) cell are essentially identical (compare Fig. $4 A$ and Fig. 4B3). All connections from sensory cells to cell 205 are polysynaptic. Sensory cells innervating the dorsal, lateral, or ventral body wall produce similar effects, and the magnitude of cell 205's response is similar regardless of whether sensory stimuli activate the $S$ interneuron (see below). These responses differ from those of cell 204, which is excited by tactile body wall stimulation but responds only weakly to intracellular stimulation of individual sensory cells (Weeks and Kristan, 1978; Kris$\tan , 1979)$.

The leech nerve cord contains a fast conducting fiber which fires transiently to photic, mechanosensory, and near field wave stimuli (Laverak, 1969; Bagnoli et al., 1972; Friesen, 1981) and which is formed by the electrically coupled interganglionic axons of the $\mathrm{S}$ cell, a segmentally iterated, unpaired interneuron (Gardner-Medwin et al., 1973; Frank et al., 1975). S cell spikes initiated at any site along the nerve cord conduct bidirectionally with an intersegmental travel time of roughly 3 to $7 \mathrm{msec}$ (Frank et al., 1975). Thus, impulses recorded in any $S$ cell soma reflect the activity of the entire fast conducting system.
Figure $5 A 1$ demonstrates that single $\mathrm{S}$ cell impulses set up in ganglion 8 produced depolarizing potentials in cell 205(9) after a delay of about 6 msec. In comparison, $\mathrm{S}$ cell impulses produced no effect on cell 204 (Fig. 5A2). The short intersegmental delay between the $\mathrm{S}$ cell spikes and cell 205 potentials (Fig. 5A1) suggested that the synapse was electrical rather than chemical, and this was borne out by simultaneous intraganglionic penetrations (Fig. $5 B$ ). Within ganglion $9, \mathrm{~S}$ cell spikes produced instantaneous potentials in cell 205 (not shown), and by passing currents between the two cells, the electrical coupling was determined to be rectifying (Fig. $5 B$ ). Figure $5 C$ illustrates the activity patterns of cell 205 and the $\mathrm{S}$ cell during a swim elicited by nerve stimulation. This stimulus excited both cells, but while cell 205 remained strongly active, the $\mathbf{S}$ cell fired only transiently and then was hyperpolarized phasically during the swim. This finding is in accord with that of Magni and Pellegrino (1978b), who monitored the fast conducting fiber with chronic electrodes in intact animals and found it to be silent during swimming. Thus, electrical coupling to the $S$ cell may contribute to the initial excitation of cell 205 by swim-eliciting stimuli, but other, more prolonged inputs serve to keep cell 205 active subsequently.

Interactions between cells 204 and 205. Because cells 


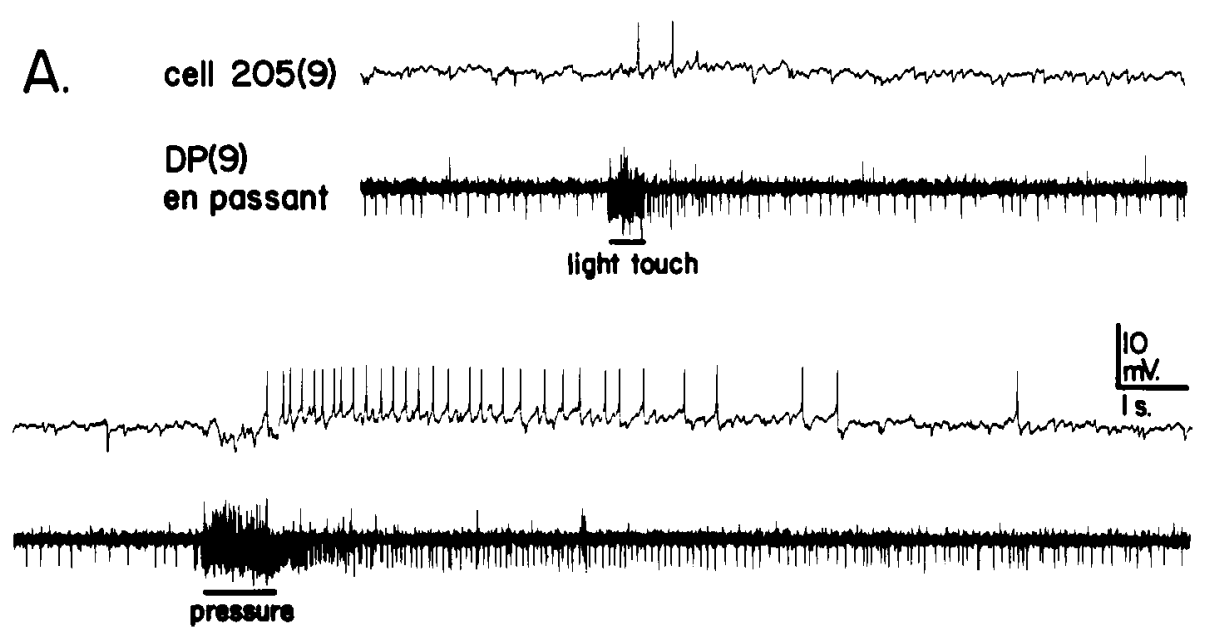

B.I. cell 205(9)
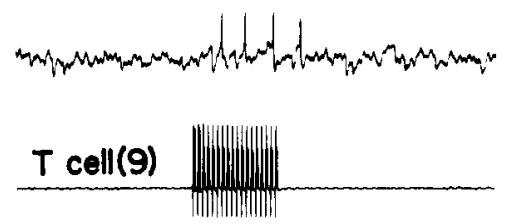

\section{2. cell 205(9)}

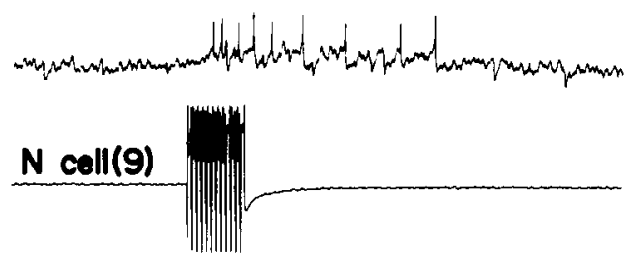

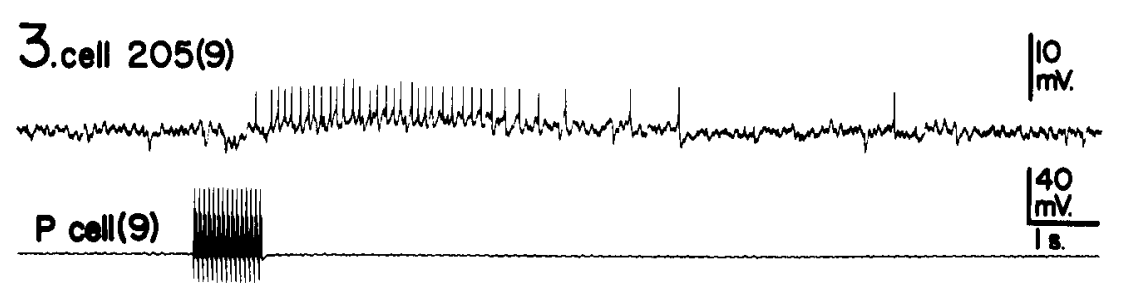

Figure 4. Tactile sensory input to cell 205. A, Direct tactile stimulation. The upper trace is an intracellular recording from cell 205(9) in an isolated nerve cord connected by the left DP(9) nerve (lower trace) to a portion of body wall; hence, the body wall was innervated by one T (touch), one $\mathrm{P}$ (pressure), and one $\mathbf{N}$ (nociceptive) sensory neuron (Nicholls and Baylor, 1968). The two lines of recordings in $A$ are continuous. For the approximate duration indicated by the first bar, the skin was stroked lightly once with the blunt tip of a small glass rod. During the second bar, the stroke was repeated but with sufficient pressure to deform the body wall. $B$, Stimulation of individual sensory neurons. In each panel, the upper trace is an intracellular recording from the same cell 205(9), while the lower traces are intracellular recordings from individual $\mathrm{T}, \mathrm{P}$, or $\mathrm{N}$ sensory neurons in ganglion 9 . In each case, the sensory neuron was driven to fire at $15 \mathrm{~Hz}$ by injected depolarizing current pulses; stimulus artifacts partially obscure sensory cell action potentials. By monitoring the presence or absence of sensory cell spikes in ipsilateral DP nerves (not shown), the body wall receptive fields of the cells were determined to be: $T$ cell, ventral or lateral; $\mathrm{P}$ cell, ventral; $\mathrm{N}$ cell, dorsal. The recordings in $A$ and $B$ are from different Hirudo preparations.

204 and 205 are the only known leech swim-initiating cells, it was of interest to compare their properties and to examine their possible interactions. Cells 204 in different ganglia are indistinguishable physiologically and affect one another only insofar as one cell can turn on swimming and thereby activate the others (Weeks and Kristan, 1978).

Figure $6 \mathrm{~A}$ demonstrates that the swim activity patterns of cells 204 and 205 are indistinguishable; in this example, both became active at the time of nerve stimulation, both fired rhythmically during the initial portion of the swim but gradually became tonically active, and both stopped firing at the end of the swim. This similarity was revealed further by measuring the firing frequencies of simultaneously penetrated cells 204 and 205 during swim episodes elicited by DP nerve stimulation $(N=9$ episodes in 3 preparations). During the first cycle of the swim bouts, the mean frequency was $22 \pm 9$ (SD) $\mathrm{Hz}$ for cell 204 and $24 \pm 11 \mathrm{~Hz}$ for cell 205 , whereas during entire swim bouts, the values were $13 \pm 5 \mathrm{~Hz}$ for cell 204 and 12 $\pm 8 \mathrm{~Hz}$ for cell 205 .

This similarity in the swim patterns of cells 204 and 205 suggested that they are coupled synaptically, receive common synaptic input, or both. To test the first possibility, pairwise recordings were made while stimulating each neuron in turn. Because stimulation of either cell can elicit swimming and thereby influence the other cell, it was necessary to test for connections using low firing frequencies. Weak depolarization of cell 204 which caused minimal motor responses in segmental nerves neither inhibited (Fig. 6B1) nor excited (Fig. 6B2) cell 205, and similarly, cell 205 neither inhibited (Fig. 6B3) nor excited 

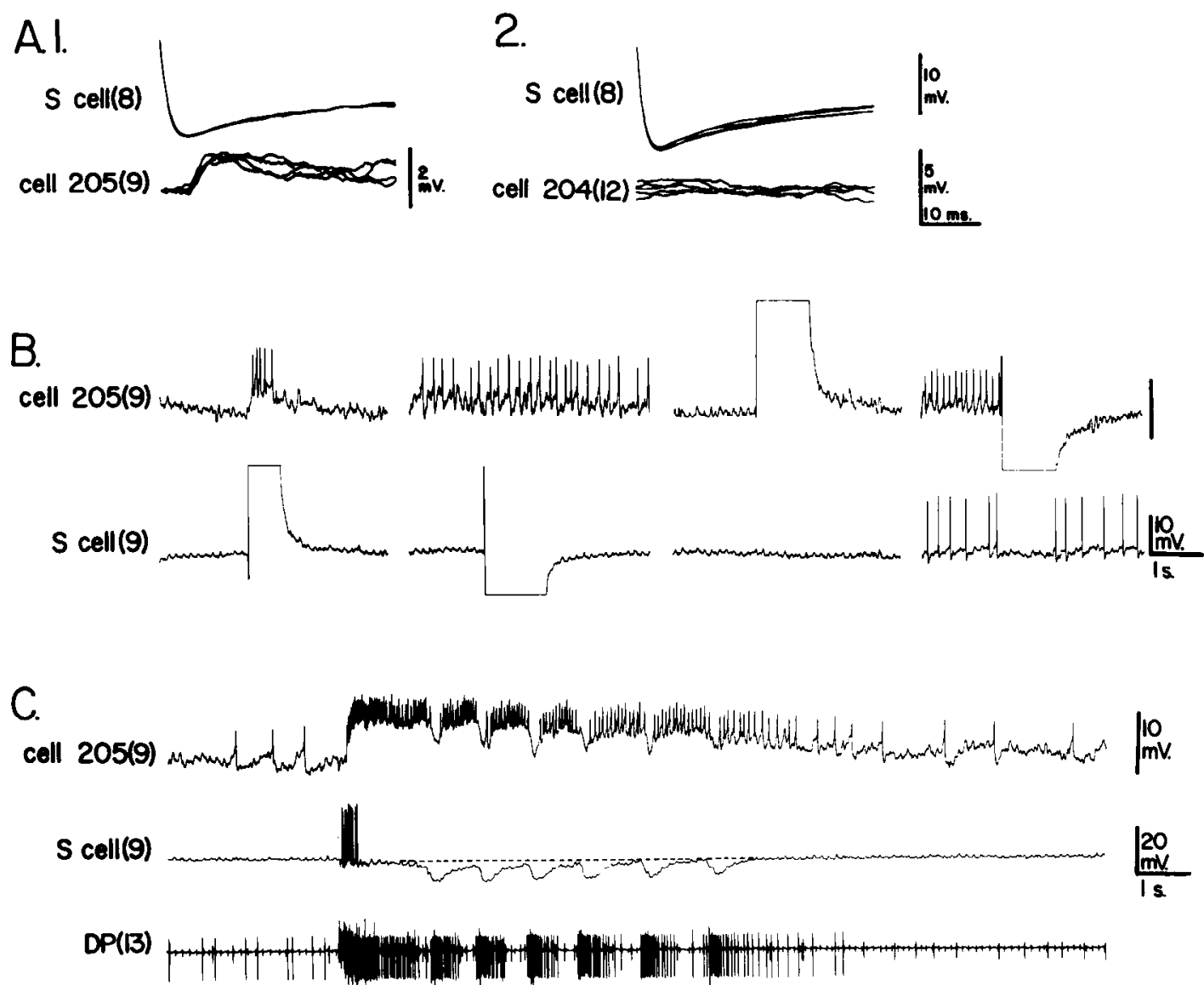

Figure 5. Connections between cell 205 and the S cell. All recordings are intracellular with the exception of the bottom trace of $C$, which is extracellular. A, Comparison of interganglionic S cell connections with cells 205 and 204. A1, Four superimposed oscilloscope sweeps triggered from intracellularly recorded $\mathrm{S}$ cell(8) action potentials (upper trace), which match EPSPs recorded intracellularly in cell 205(9) (lower trace). A2, Five superimposed oscilloscope sweeps triggered from the same $\mathrm{S}$ cell (upper trace) showing no response in cell 204(12) (lower trace). B, Intraganglionic connections between cell 205 and the $\mathrm{S}$ cell. During the upward or downward deflection of each trace, respectively, 10-nA depolarizing or hyperpolarizing current was injected intracellularly. In the second and fourth data segments, the postsynaptic neurons were activated by injected depolarizing current. Depolarizing current passed from the $S$ cell to cell 205, and hyperpolarizing current passed from cell 205 to the $S$ cell. In this example, cell 205 hyperpolarization did not cause a shift in the $\mathrm{S}$ cell's membrane potential, but in most experiments, it did. Electrical coupling between the two cells was consistently stronger in Macrobdella than in Hirudo. C, Cell 205 and S cell swim activity patterns. The swim episode was elicited by delivering a train of electrical pulses to DP(14) (not shown) for the duration indicated by the bar. The recordings in $A$ to $C$ are from different Hirudo isolated nerve cord preparations.

(Fig. 6B4) cell 204. In contrast, stronger stimulation produced effects which were variable and complex (Fig. $6, B 5$ and $B 6$ ). In Figure $6 B 5$, cell 205 initially produced excitation and then inhibition in cell 204 . However, segmental nerve bursts indicate that this response consisted of a swim lasting only one cycle: cell 204's depolarization corresponded to its ventral "on" phase, and its hyperpolarization occurred, as in swimming, during dorsal excitor bursts. Cell 205 similarly exhibited inhibition during the dorsal bursts. In Figure 6B6, cell 205 depolarization produced a sustained dorsal burst and accordingly, inhibition of cell 204. In no case did spikes in one cell match synaptic potentials in the other cell, nor did hyperpolarizing current (up to $10 \mathrm{nA}$ ) passed into either cell affect the other (data not shown). These results demonstrate that cells 204 and 205 interact in the same way as do cells 204 located in different ganglia (Weeks and Kristan, 1978).

This lack of direct synaptic connections between cells 204 and 205 suggests that the similarity in their swim patterns is due to a similarity in synaptic input. Because of the difficulty in discerning discrete synaptic potentials in these cells during swimming, it was not possible to identify any common inputs during this behavior. However, these cells receive common synaptic input between swim bouts (Fig. 9) so that common input may be present as well during swims.

Swim initiation by cells 204 and 205. To examine further the participation of cells 204 and 205 in swim initiation and maintenance, swim episodes were initiated during simultaneous penetrations by stimulating each neuron in turn (Fig. 7). Figure $7 \mathrm{~A}$ illustrates one way in which swims initiated by cell 205 sometimes differ from those initiated by cell 204: there is a preferential activation of swimming in the anterior end of the nerve cord. In this example, the first few burst cycles were restricted to the anterior half of the cord with posterior segments joining in only later. During swims initiated in the same preparation by cell 204 stimulation, the first burst cycle encompassed all segments (Fig. $7 B$ ) as is characteristic 


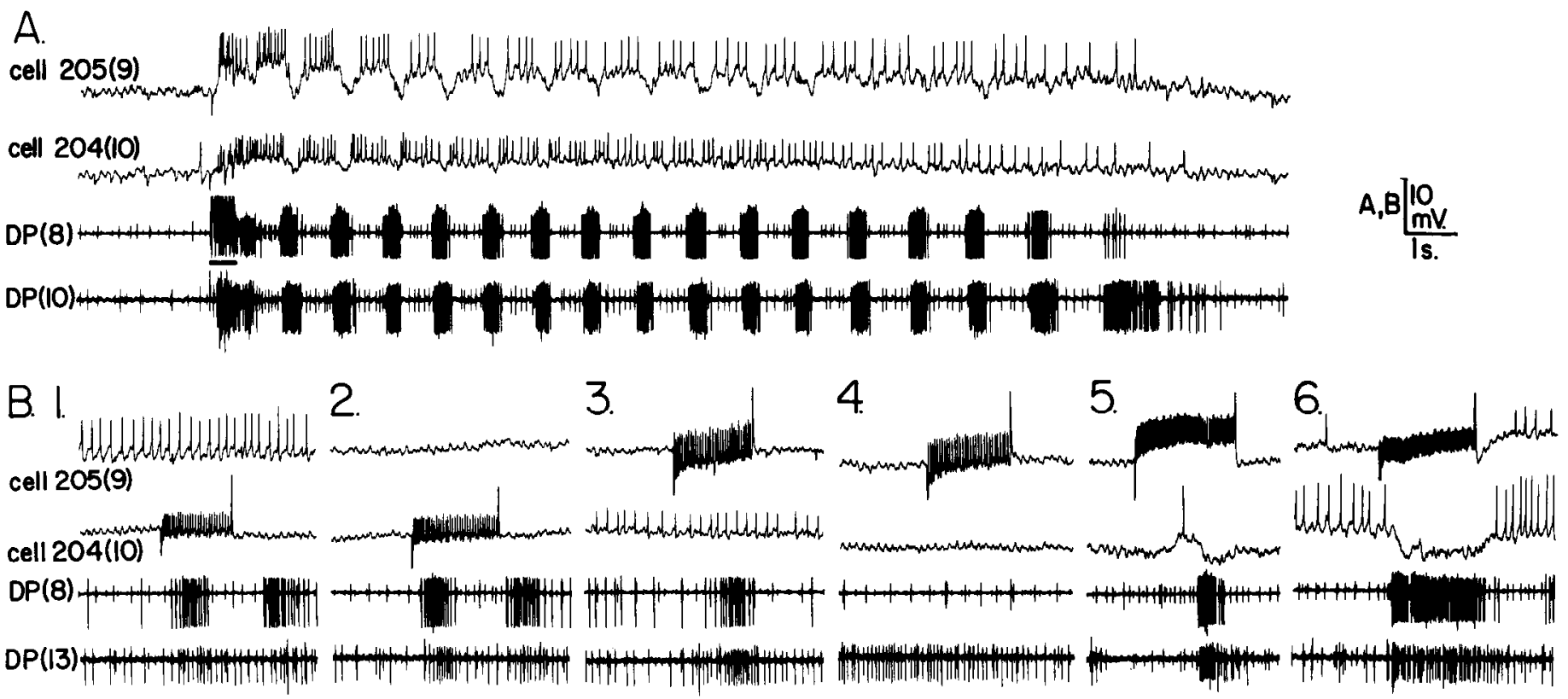

Figure 6. Swim activity patterns $(A)$ and synaptic interactions $(B)$ of cells 204 and 205 . In each panel, the upper two traces are intracellular, while the lower two traces are extracellular recordings showing dorsal bursts in DP nerves. The swim episode in $A$ was elicited by brief electrical stimulation of $\mathrm{DP}(8)$ (bar). In $B$, neurons were stimulated to fire by intracellularly injected depolarizing current. The preparations in $A$ and $B$ were Hirudo isolated nerve cords.

of cell 204 (Weeks and Kristan, 1978). In semi-intact animals, cell 205 stimulation sometimes causes swim undulations exclusively in the anterior part of the body (J. C. Weeks and W. B. Kristan, unpublished observations). Approximately $20 \%$ of the cells 205 examined showed some degree of asymmetrical swim activation, but because of suction electrode placements, this effect would have been missed in many preparations.

The preferential activation of swimming in anterior segments by cell 205 suggests that this neuron might initiate swims by way of the synaptic interactions of its anteriorly projecting axon (Fig. 1). This possibility was tested as follows. In 3 isolated nerve cords, cell 205(9) was penetrated and determined to drive swimming. Then, the connectives between ganglia 8 and 9 were severed. In each preparation, this procedure eliminated cell 205 's swim-initiating capability although the remaining nerve cord (ganglia 9 to 20) swam readily in response to stimulation of nerves or cell 204. Hence, cell 205's purely intraganglionic connections appear insufficient to activate swimming. Similar section of the nerve cord adjoining a cell 204 does not destroy its swim-initiating ability (Weeks, 1981), possibly because its axons project bidirectionally (Weeks and Kristan, 1978; Weeks, 1981).

During swims initiated by stimulation of one cell 204, all other cells 204 in the nerve cord become active as swimming begins (Weeks and Kristan, 1978). Figure 7 shows that cell 205 shares this property with cell 204 . In Figure $7 A$, cell 204 exhibited only modest activity while the swim pattern was confined to anterior segments, but once swimming spread to the whole cord, its firing frequency increased to a more typical level. Cell 204's activity pattern during swims elicited by cell 205 stimulation was the same as during swims elicited in the same preparation by other means. When cell 204 was stimulated to initiate swimming, cell 205 was active throughout the swim bout (Fig. 7B).

Figure 7 re-emphasizes that each cell 204 or 205 can initiate swimming independently and does not require concomitant activity in the other swim-initiating cells. The other cells become active once the swim begins (Fig. 7; Weeks and Kristan, 1978), but this activity contributes only to the maintenance of the swim.

Modulation of swimming rate by cells 204 and 205. Independent of the initiating stimulus, the swim cycle period is always shortest at swim onset and then gradually lengthens until the bout terminates (Kristan and Calabrese, 1976; Weeks and Kristan, 1978; Weeks, 1982b). This progression can be altered by artificially elevating the firing rate of a cell 204, causing the swim cycle period to be shortened for at least the duration of cell 204 stimulation; within limits, the effects of simultaneously stimulating two cells 204 in this way are additive (Weeks and Kristan, 1978). Figure 8 demonstrates that cell 204 and cell 205 activity summate in a similar manner. The swim bout was initiated by depolarizing cell 204 to fire at approximately $40 \mathrm{~Hz}$ (upper graph), followed shortly by similar depolarization of cell 205 (middle graph). During the ensuing 17-cycle swim episode, depolarization of one or the other cell was terminated briefly for the times marked by shaded bars. On both occasions, the swim cycle period (bottom graph) lengthened considerably. The cycle period was shortest when both cells were stimulated (i.e., cycles 2 to 6,9 and 10 , and 14 to 17). Hence, the excitatory effects of individual cells 204 and 205 combined. This result was obtained only when the stimulated cell 205 drove normal swims; when cell 205 drove dorsal sustained swims, the cycle period was lengthened (e.g., Fig. 2B1).

Common synaptic input to cells 204 and 205. Cells 204 

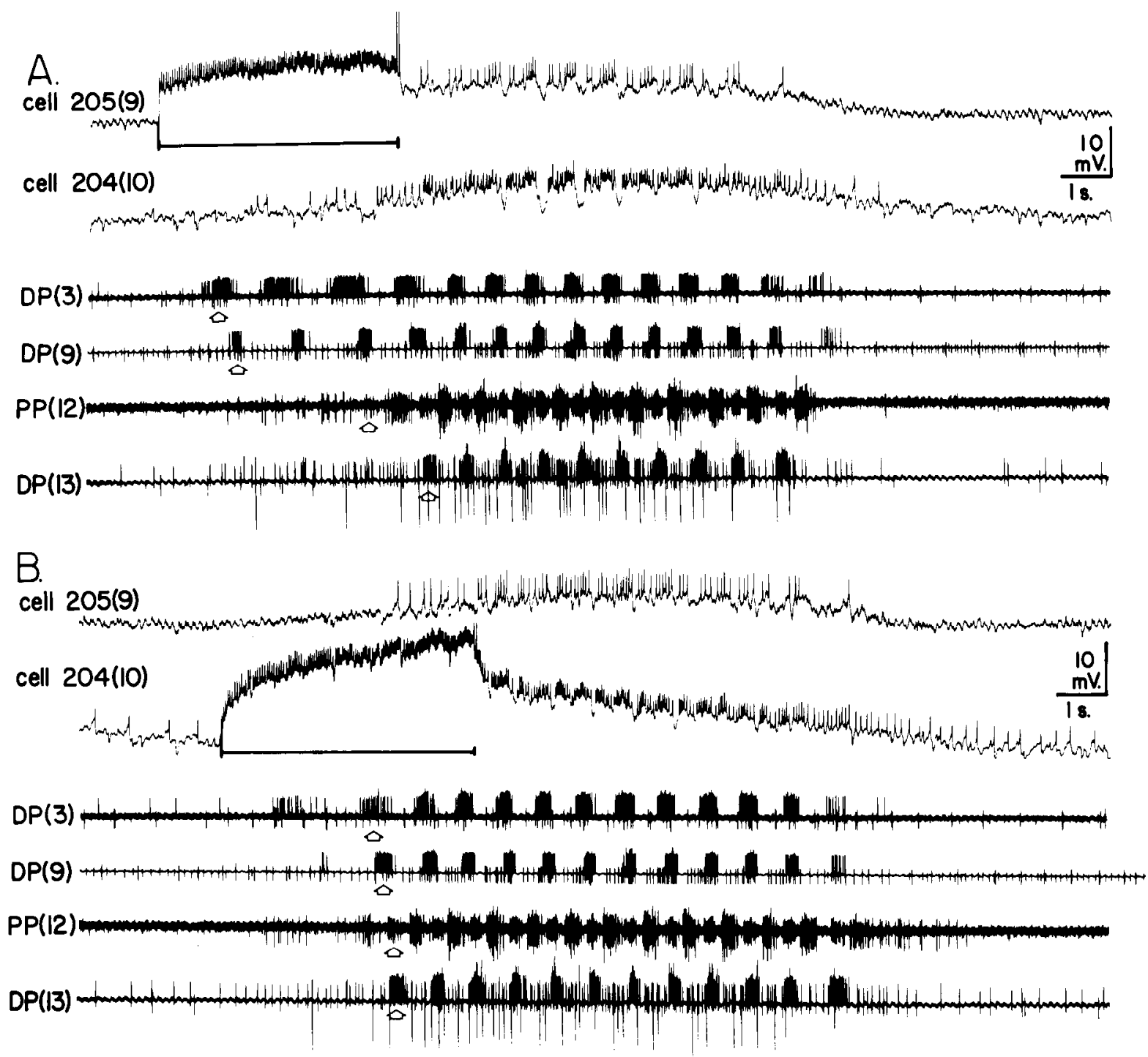

Figure 7. Activity of cells 204 and 205 during swim initiation. In both panels, the upper two traces are intracellular, while the lower four traces are extracellular recordings. DP(3) and DP(9) show dorsal bursts, while DP(13) shows some "modulated" units (Ort et al., 1974) in addition to dorsal bursts. The PP(12) nerve (posterior branch of the posterior nerve) shows dorsal and ventral bursts. For the times indicated by the bars, depolarizing current was injected into cell 205(9) $(A)$ or cell 204(10) $(B)$. The arrowheads mark the first dorsal burst in each nerve. The recordings in $A$ and $B$ are from the same $H$ irudo isolated nerve cord.

and 205 receive both common inhibitory (Fig. $9 A$ ) and common excitatory (Fig. $9 B$ ) synaptic input. The prominent IPSPs shown in Figure $9 A$ were observed in many preparations between swim bouts, occurring in all cells 204 (Weeks, 1982a) and 205 in the nerve cord with a 23to 25 -msec intersegmental delay between their occurrences in successively more posterior ganglia. The neurons which produce the IPSPs are presently unidentified, but because the IPSPs almost invariably disappear during swimming (Weeks, 1980; 1982a), these neurons may help to keep swim-initiating cells inactive during other behaviors.

Segmental nerve stimulation in quiescent preparations elicits common EPSPs in cells 204 and 205; by varying the segmental location of the stimulus, the order of arrival of EPSPs in swim-initiating interneurons located in different segments can be varied (Fig. 9B). The similar appearance of the EPSPs in Figure 9, $B 1$ to $B 3$, and their constant intersegmental delay suggest that they were produced by the same presynaptic neuron(s), which could be activated by nerve stimulation delivered in at least three different locations. The identity of the presynaptic neuron(s) is unknown, but it presumably contributes to the widespread excitation of swim-initiating cells caused by nerve stimulation (Figs. 3, 5, and 6 ).

Common output connections of cells 204 and 205. Three neurons are known to be postsynaptic to cell 204 (Weeks, 1980, 1982a, b): cell 109, a motor neuron which excites lateral dorsoventral "flattener" muscles (Stuart, 1970; Ort et al., 1974); cell 117, a motor neuron which excites medial flattener muscles (B. G. Wallace, personal communication); and cell 208, a CPG interneuron (Weeks, 1980, 1982b). The flattener motor neurons are quasitonically active during swimming, ensuring a hydrodynamically favorable body profile (Ort et al., 1974; Weeks, 1982a). Cell 205 produces constant latency EPSPs in anterior cells 109 (Fig. 10A) and cells 117 (Fig. 10B) for a distance of at least 6 segments, the longest distance 


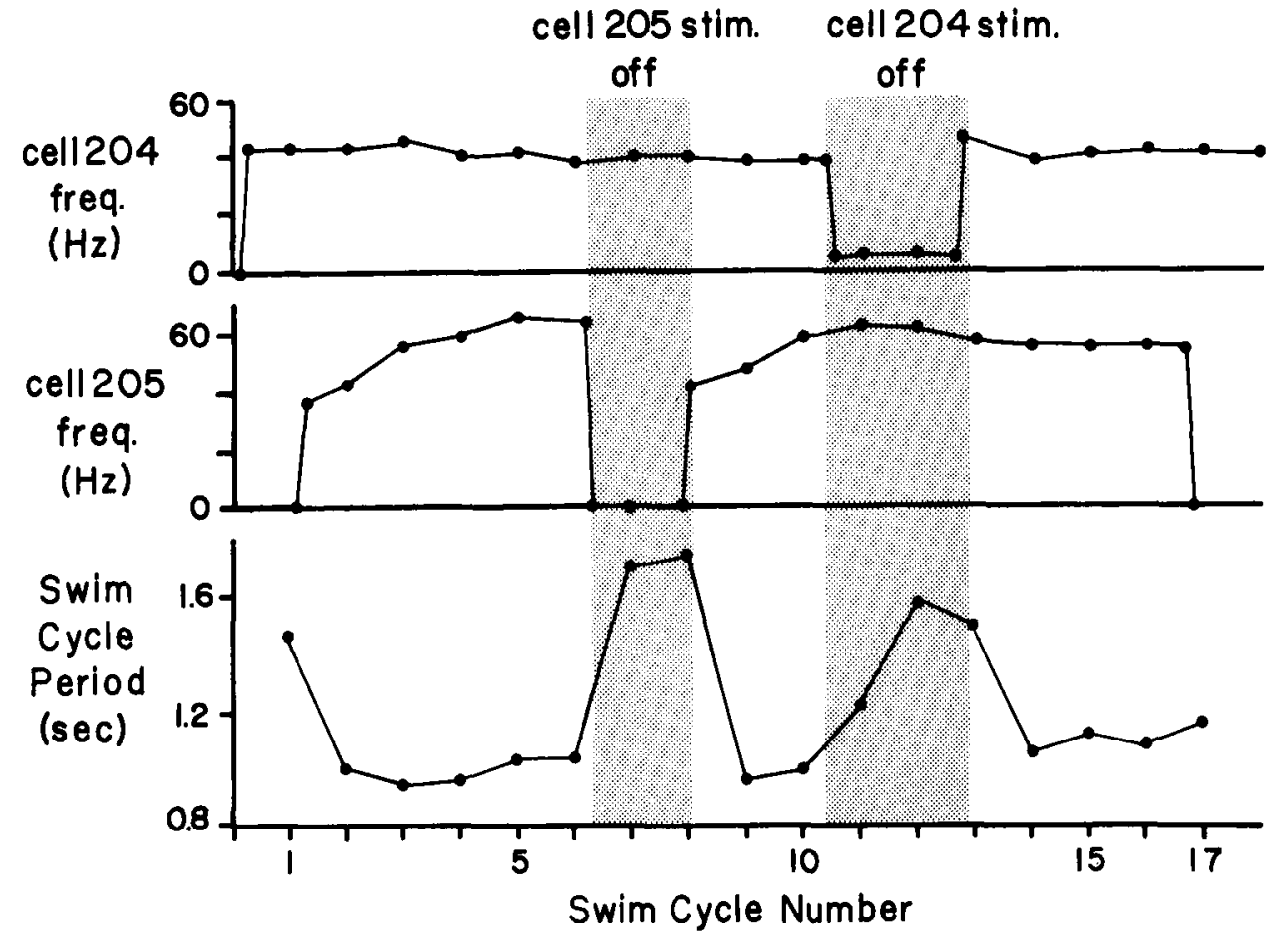

Figure 8. Effects of cell 204 and cell 205 firing frequency on the swim cycle period. Data were taken from a swim episode lasting 17 cycles (abscissa) which was driven by intracellular injection of depolarizing current into cell 204(10) (top graph) and cell 205(9) (middle graph) in a Hirudo isolated nerve cord. During each swim cycle, the average firing frequencies of cells 204 and 205 and the average swim cycle period (interval between successive dorsal phase bursts) were measured and are shown plotted as simultaneous graphs. The swim was initiated by depolarizing cell 204 such that it fired continuously at about $40 \mathrm{~Hz}(c y c l e ~ 0)$. This level of cell 204 stimulation was maintained for the entire episode except for an interval from the middle of the $10 t h$ swim cycle to cycle 13. Cell 205 was depolarized similarly during cycles 1 to 6 and 8 to 16. The shaded bars mark the times during which stimulation of cell 205 (first bar) or cell 204 (second bar) was turned off, causing lengthened swim cycle periods (bottom graph). When cell 205 depolarization was terminated a second time (cycle 17), the swim ended. The swim cycle period was shortest when both cells 204 and 205 were stimulated and longest for the times during which just one cell was stimulated (bars).

examined. Intraganglionically, cells 205 and 109 are linked by a rectifying electrical connection, allowing cell 205 to depolarize cell 109 (data not shown). Cell 205 also produces time-locked EPSPs in the CPG interneuron, cell 208, in anterior ganglia (Fig. 10C) for a distance of at least 7 segments (Weeks, 1982b). Cell 205's synaptic connections are, in each case, identical to those made by cell 204 (Weeks, 1980, 1982a, b), except that cell 205 makes unidirectional rather than bidirectional interganglionic connections as predicted by its unidirectional axonal projection (Fig. 1).

\section{Discussion}

Cell 205 is endowed with a variety of functional properties not previously found combined within single leech neurons: it has the attributes of both swim-initiating and pattern-generating interneurons, and its inputs from primary mechanoreceptors and the multimodal fast conducting system suggest a sensory function. Cell 205 is also unique in having a limited segmental distribution, and as will be considered below, cell 205 may, in fact, be a segmentally differentiated homolog of cell 204 .

Cell 205 as a swim initiator and CPG interneuron. Evidence that cell 205 normally participates in the initiation and maintenance of swimming in intact animals includes: (1) it is excited by all swim-eliciting stimuli (Figs. 3, 4, 5C, 6A, $7 B$, and $9 B$ ); (2) in response to such stimuli, its activity precedes and overlaps the initiation of swimming (Figs. $3,5 C$, and $6 A$ ); (3) its activity is sufficient to initiate, maintain, and modulate the rate of swimming (Figs. 2, 7A, and 8); and (4) it is active throughout swim episodes elicited in any fashion (Fig. 3, $5 C, 6 A$, and $7 B$ ). These attributes are all shared with cell 204 although, significantly, the following details vary. First, the synaptic pathways by which sensory stimuli excite the two interneurons differ in that both cells are excited by tactile body wall stimulation, but only cell 205 is excited by individual primary mechanoreceptor neurons (Fig. 4; Weeks and Kristan, 1978; Kristan, 1979) and the $S$ cell (Fig. 5). Second, although both interneurons drive normal swimming behavior, cell 205 can, in addition, drive dorsal sustained swims (Fig. $2 B$ ). This fundamental dissimilarity results from the qualitatively different interactions of the two interneurons with the CPG. 'This is best demonstrated by resetting experiments, in which large depolarizing pulses injected into cell 205 arrest the pattern in dorsal phase (Fig. $3 B$ ), whereas similar pulses injected into cell 204 cause an overall acceleration of the pattern that outlasts the pulse duration and which does not involve any changes in pattern phasing (Weeks and Kristan, 1978; J. C. Weeks, unpublished observations). Hence, cell 204 exerts an exclusively tonic effect on the CPG, whereas cell 205 can exert tonic (Fig. $2 A$ ) or phasic (Fig. $3 B$ ) effects. A final difference between the two 

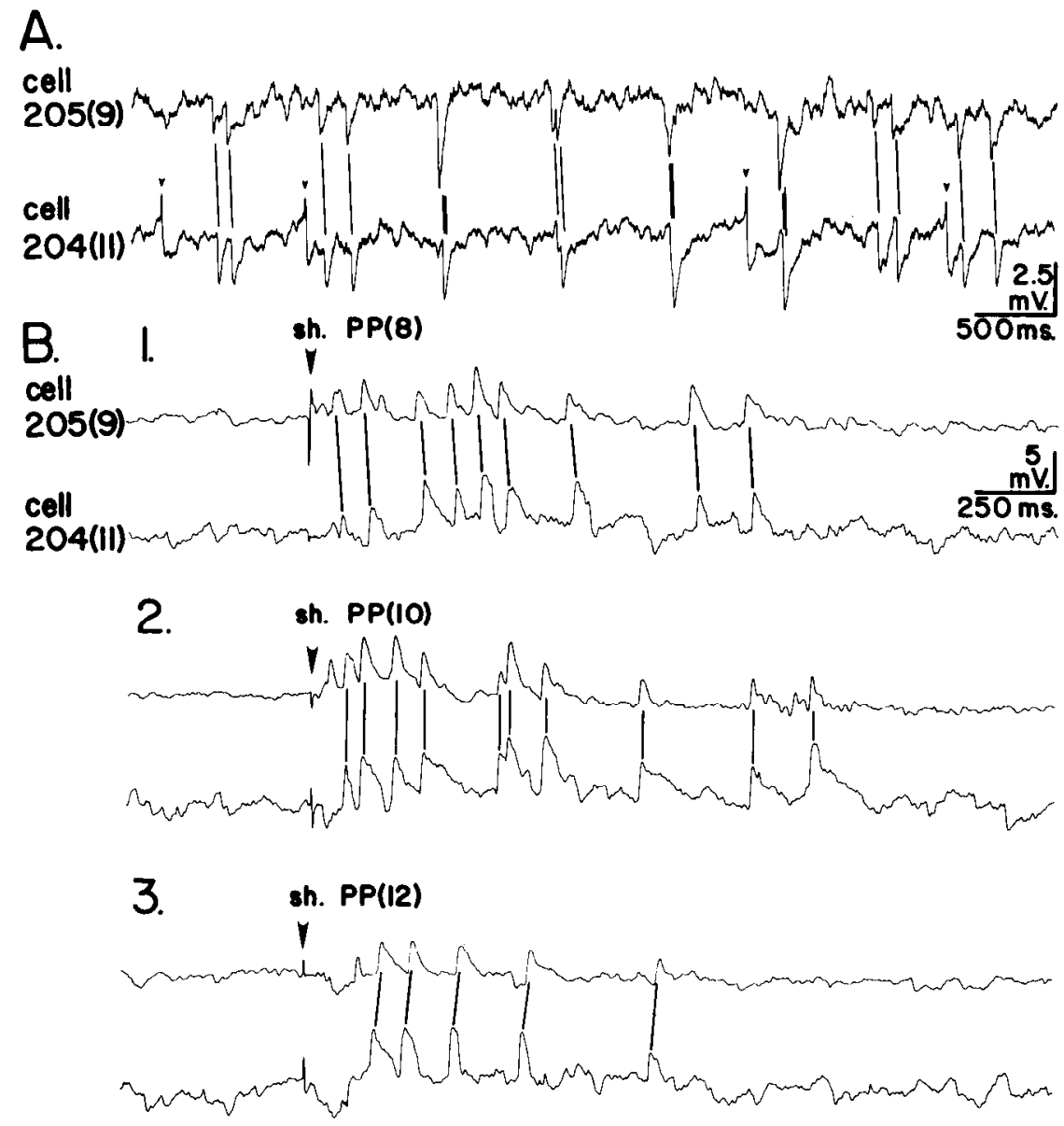

Figure 9. Common inhibitory $(A)$ and excitatory $(B)$ synaptic input to cells 204 and 205. $A$, Common IPSPs. Both traces are intracellular recordings. The lines connect the occurrences of large IPSPs common to both neurons; arrowheads mark action potentials in cell 204(11). The preparation was a Hirudo isolated nerve cord. $B$, Common EPSPs. Each panel shows simultaneous intracellular recordings from cell 205(9) and cell 204(11). Both cells were hyperpolarized to prevent firing. In B1 to B3, a single electrical shock (sh.) was delivered to a PP nerve either anterior $(\mathrm{PP}(8))$, posterior $(\mathrm{PP}(12))$, or midway between (PP(10)) the two interneurons. Stimulus duration and voltage were adjusted to be at threshold for eliciting the EPSPs. The lines connect the occurrences of EPSPs common to both neurons. The intersegmental delay between EPSPs recorded in the two cells was about $15 \mathrm{msec} / \mathrm{segment}$. When PP(8) was shocked (B1), EPSPs in cell 205(9) preceded those in cell 204(11); when PP(12) was shocked $(B 3)$, the opposite occurred. Shock of $\mathrm{PP}(10)(B 2)$ caused simultaneous EPSPs in both interneurons. The preparation was a Macrobdella isolated nerve cord.

interneurons is cell 205's ability to activate swimming preferentially in anterior segments (Fig. $7 A$ ). This may be accounted for by cell 205's unidirectional axonal projection (Fig. 1) as opposed to the bidirectional projection of cell 204 (Weeks and Kristan, 1978; Weeks, 1981). In fact, cell 204 can be made to have a similar unidirectional effect by cutting one of its two interganglionic axons (Weeks, 1980). The possibility that the anterior undulations sometimes elicited by cell 205 correspond to a behavior distinct from locomotory swimming (e.g., ventilation; see Magni and Pellegrino, 1978b) was not examined in these experiments. These differences aside, cells 204 and 205 are indistinguishable in most physiological respects even insofar as making the same output connections to some swim motor neurons and interneurons (Fig. 10) and in receiving identical synaptic inputs from at least two sources (Fig. 9).

Cell 205's strong interaction with the CPG is evidenced both by its resetting ability (Fig. $3 B$ ) and the production of dorsal sustained swims (Fig. $2 B$ ). Because its activity is not invariably cyclic and pending the determination of its synaptic connections with other CPG cells, cell 205 cannot, at this time, be considered an element of the CPG. However, its activity is often strongly cyclic (e.g., Fig. $5 C$ ) and it clearly has access to the CPG when firing at physiological frequencies. Unidentified neurons which fire tonically during swimming and can reset the pattern have been encountered previously and conjectured to be sensory interneurons (Poon, 1976).

Cell 205 stimulation gives rise to two opposing forces: first, because of its swim-initiating capability, it promotes rhythmic swimming (tonic effect), but second, it tends to impede the pattern by arresting it in dorsal phase (phasic effect). In the present experiments, the interplay between these two tendencies resulted in swim patterns ranging from normal (Fig. 2A) to rhythmic dorsal sustained (Fig. $2 B 1$ ) to, in the extreme case, total arrest in dorsal phase (Figs. $2 B 2,3 B$, and $6 B 6$ ). The variability with which cell 205 elicits the different swim patterns cannot entirely be explained at this time. Cell 205's firing rate is not the 

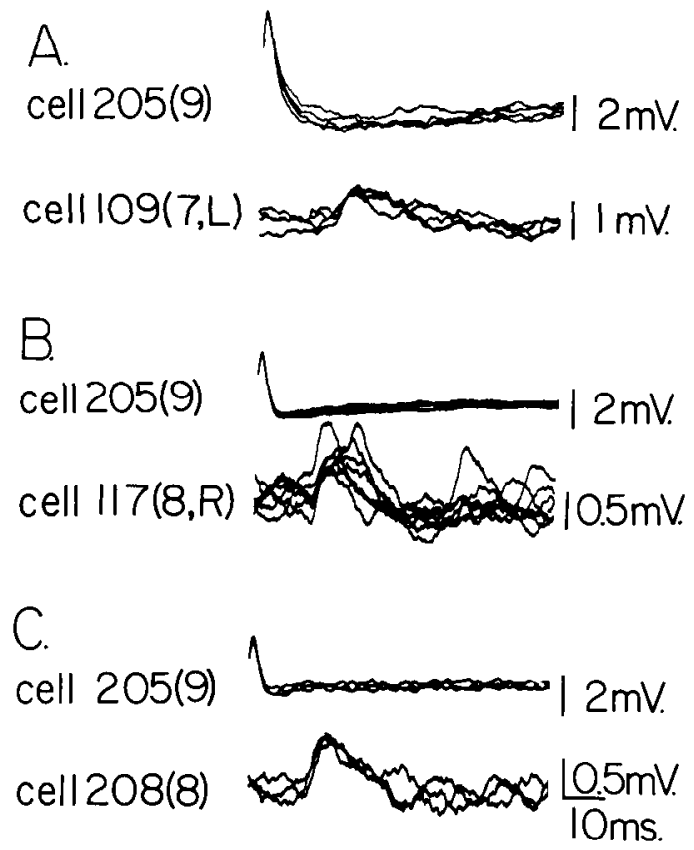

Figure 10. Interganglionic excitatory connections from cell 205 to flattener motor neurons and cell 208. A, Four superimposed oscilloscope sweeps triggered from cell 205(9) spikes (upper trace) which match EPSPs in the excitor of lateral flattener muscles, cell 109(7, L) (lower trace). B, Seven sweeps showing EPSPs in the excitor of medial flattener muscles, cell $117(8, \mathrm{R})$, which match cell $205(9)$ spikes. $C$, Three sweeps showing EPSPs in the CPG interneuron, cell 208(8), which match spikes in cell 205(9). The preparations were different Hirudo isolated nerve cords with body wall flaps left attached in $A$ and $B$ for motor neuron identification.

absolute determinant, because in the frequency range tested ( 5 lo $100 \mathrm{H} z$, driven by currents up to $2 \mathrm{nA}$ ), there was no correlation between the firing rate and the type of pattern evoked. However, there was less variability with the larger currents (4 to $10 \mathrm{nA}$ ) used in resetting experiments, which almost invariably arrested, rather than accelerated, the pattern. Thus, at low stimulation levels, pattern type cannot be predicted, but with larger currents, cell 205's phasic effect predominates.

The preferential activation of the dorsal phase by cell 205 suggests that it has synaptic access to the CPG interneurons which generate this phase. Relevant to this possibility is that cell 205 excites the CPG interneuron, cell 208, in all ganglia anterior to its own (Fig. 10; Weeks, 1982b). Cell 208 bursts strongly in dorsal phase and, by way of a posteriorly directed axon, makes functionally important monosynaptic excitatory connections onto dorsal excitor motor neurons all along the nerve cord (Weeks, 1982b). However, these connections cannot account entirely for cell 205's activation of dorsal phase, since cell 204 connects similarly with cell 208 (Weeks, $1982 \mathrm{~b}$ ) but exhibits no phase-specific effects. At this time, possible differences in the connectivity of cells 204 and 205 with other CPG interneurons remain unexamined; it is known that cell 204 does not contact any of the four "oscillator" cells (Weeks, 1982a) synaptically, but similar pairwise recordings involving cell 205 have not yet been accomplished.

Sensory role of cell 205. Although swimming is pro- duced by a CPG and does not require afferent feedhack, in intact animals, sensory input serves both to trigger the initiation of swims and to modify adaptively the ongoing motor pattern. With respect to swim initiation, mechanosensory stimuli elicit swimming in large part, if not exclusively, via widespread excitation of the swim-initiating interneurons. During swimming, brief tactile stimulation (J. C. Weeks, unpublished observations) or stretch (Kristan and Calabrese, 1976) of a portion of body wall in nearly isolated nerve cord preparations causes motor pattern resetting as does localized restriction of body undulations in intact animals (Kristan and Stent, 1976). However, the neuronal pathways by which sensory information modifies CPG output once the pattern is underway have not been determined. Cell 205, because it receives sensory input (Figs. 4 and 5) and can influence CPG phasing when firing at frequencies within the range of these elicited by sensory stimuli, could serve such a modulatory function.

The finding that cell 205 and the $\mathbf{S}$ cell are coupled electrically (Fig. 5) was unexpected, given that the fast conducting system has been proposed to trigger the whole body shortening reflex (Magni and Pellegrino, 1978a), a behavior incompatible with swimming (Ort et al., 1974). However, other findings also suggest that this system is not involved exclusively with shortening, at least in hirudinid leeches. For instance, intracellular stimulation of $\mathrm{S}$ cells in semi-intact preparations causes only weak and erratic behavioral responses (W. B. Kristan, M. P. Nusbaum, and J. C. Weeks, unpublished observations), and the fast conducting system fires only transiently to sensory stimuli and is silent during the initiation of subsequent behaviors (Laverack, 1969; Magni and Pellegrino, 1978b). These observations suggest that rather than "commanding" a particular behavior, activity in the fast conducting system serves to alert the animal to a change in its environment; the behavioral response, if any, is determined by the activation of appropriate interneurons. This apparently occurs at swim initiation, when the $S$ cell contributes to the early excitation of cell 205 , but other, more prolonged inputs keep cell 205 active (Fig. 5C).

Are cells 204 and 205 segmentally differenliated homologs? In addition to their similar physiological properties, three morphological features suggest that cells 204 and 205 are segmentally differentiated homologs: (1) cell 204 and cell 205 have never been found in the same ganglion even in the two instances in which cell 205 was found in ganglion 8 or 10 as well as in ganglion 9; (2) both cells are unpaired, with somata of similar size and ganglionic position; and (3) their arborizations are indistinguishable except for differences in the direction of their interganglionic axonal projections in Faivre's nerve. If they are truly homologs, the two cells would represent developmental alternatives; for example, during neurogenesis, both cells might be present early, but one dies, or, alternatively, a single undifferentiated cell could become one or the other. In the former situation, one might expect to find occasionally both a cell 204 and a cell 205 in a ganglion (especially when cells 205 are present in other than the 9th ganglion), just as supernumerary leech sensory and motor neurons are found sometimes (Kuffler and Muller, 1974). However, this has not yet been ob- 
served. Supporting the second developmental scenario was the finding of a neuron with properties of both cells (J. C. Weeks, unpublished observation). This neuron, located in ganglion 9, resembled cell 205 in that it drove both normal and dorsal sustained swims and reset swimming but lacked cell 205's characteristic connections with $S$ and $P$ cells. It further resembled cell 204 in exhibiting "doublet" spikes, diagnostic of bidirectionally projecting axons. Unfortunately, an attempted dye fill of the cell was unsuccessful. This neuron appeared not to have differentiated strictly as either a cell 204 or cell 205 but as a combination of the two.

At this time, the purpose of segmental specialization of swim-initiating interneurons is unknown. Leeches respond differently to tactile stimulation depending upon the segmental location of the stimulus (Kristan et al., 1982), but any dependence of behavioral responses on the segmental distribution of swim-initiating interneurons remains unexplored. There are precedents for both segment-specific neurons and segmentally differentiated homologs in the leech. For instance, penile motor neurons (Zipser, 1979), serotonin-containing "E" neurons (Lent and Frazer, 1977), and heart interneurons (HN cells; Thompson and Stent, 1976) occur only in specific segments; furthermore, HN cell homologs show segmentspecific morphology and connectivity (Shafer and Calabrese, 1981). Final determination of the developmental origin and possible homology of cells 204 and 205 and other leech neurons can be made by the determination of cell lineage (Weisblat et al., 1980) and by making intracellular recordings during the time of initial axonal outgrowth (Kuwada and Kristan, 1981), strategies which have been fruitful in establishing segmental homologies in other species (e.g., Bate et al., 1981).

\section{References}

Bagnoli, P., M. Brunelli, and F. Magni (1972) A fast conducting pathway in the central nervous system of the leech Hirudo medicinalis. Arch. Ital. Biol. 110: 35-51.

Bate, M., C. S. Goodman, and N. C. Spitzer (1981) Embryonic development of identified neurons: Segment-specific differences in the $\mathrm{H}$ cell homologues. J. Neurosci. 1: 103-106.

Delcomyn, F. (1980) Neural basis of rhythmic behavior in animals. Science 210: 492-498.

Frank, E., J. K. S. Jansen, and E. Rinvik (1975) A multisomatic axon in the central nervous system of the leech. J. Comp. Neurol. 159: 1-13.

Friesen, W. O. (1981) Physiology of water motion detection in the medicinal leech. J. Exp. Biol. 92: 255-275.

Friesen, W. O., and G. S. Stent (1977) Generation of a locomotory rhythm by a neural network with recurrent cyclic inhibition. Biol. Cybern. 28: 27-40.

Friesen, W. O., M. Poon, and G. S. Stent (1978) Neuronal control of swimming in the medicinal leech. IV. Identification of a network of oscillatory interneurones. J. Exp. Biol. 75: 25-43.

Gardner-Medwin, A. R., J. K. S. Jansen, and T. Taxt (1973) The "giant" axon of the leech. Acta Physiol. Scand. 87: 30A-31A.

Kling, U., and G. Szekely (1968) Simulation of rhythmic nervous activities. I. Function of networks with cyclic inhibitions. Kybernetik 5: 89-103.

Kristan, W. B., Jr. (1979) Neuronal changes related to behavioral changes in chronically isolated segments of the medicinal leech. Brain Res. 167: 215-220.
Kristan, W. B., Jr. (1980) Generation of rhythmic motor patterns. In Information Processing in the Nervous System, $\mathrm{H}$. M. Pinsker and W. D. Willis, Jr., eds., pp. 241-261, Raven Press, New York.

Kristan, W. B., Jr., and R. L. Calabrese (1976) Rhythmic swimming activity in neurones of the isolated nerve cord of the leech. J. Exp. Biol. 65: 643-668.

Kristan, W. B., Jr., and G. S. Stent (1976) Peripheral feedback in the leech swimming rhythm. Cold Spring Harbor Symp. Quant. Biol. 40: 483-493.

Kristan, W. B., Jr., G. S. Stent, and C. A. Ort (1974a) Neuronal control of swimming in the medicinal leech. I. Dynamics of the swimming rhythm. J. Comp. Physiol. 94: 97-119.

Kristan, W. B., Jr., G. S. Stent, and C. A. Ort (1974b) Neuronal control of swimming in the medicinal leech. III. Impulse patterns of motor neurons. J. Comp. Physiol. 94: 155-176.

Kristan, W. B., Jr., S. J. McGirr, and G. V. Simpson (1982) Behavioral and mechanosensory neurone response to skin stimulation in leeches. J. Exp. Biol. 96: 143-160.

Kuffler, D. P., and K. J. Muller (1974) The properties and connections of supernumerary sensory and motor nerve cells in the centrul nervous system of an abnormal leech. J. Neurobiol. 5: 331-348.

Kuwada, J. Y., and W. B. Kristan, Jr. (1981) Development of identified neurons in the leech CNS. Soc. Neurosci. Abstr. 7: 3.

Laverack, M. S. (1969) Mechanoreceptors, photoreceptors and rapid conduction pathway in the leech, Hirudo medicinalis. J. Exp. Biol. 50: 129-140.

Lent, C. M., and B. M. Frazer (1977) Connectivity of the monoamine-containing neurones in central nervous system of leech. Nature 266: 844-847.

Macagno, E. R. (1980) The number and distribution of neurons in leech segmental ganglia. J. Comp. Neurol. 190: 283-302.

Magni, F., and M. Pellegrino (1978a) Neural mechanisms underlying the segmental and generalized cord shortening reflexes in the leech. J. Comp. Physiol. 124: 339-351.

Magni, F., and M. Pellegrino (1978b) Patterns of activity and the effects of activation of the fast conducting system on the behaviour of unrestrained leeches. J. Exp. Biol. 76: 123-135.

Muller, K. J., and S. A. Scott (1981) Transmission at a "direct" electrical connexion mediated by an interneurone in the leech. J. Physiol. (Lond.) 311: 565-583.

Nicholls, J. G., and D. A. Baylor (1968) Specific modalities and receptive fields of sensory neurons in the CNS of the leech. J. Neurophysiol. 31: 740-756.

Nicholls, J. G., and D. Purves (1970) Monosynaptic chemical and electrical connexions between sensory and motor cells in the central nervous system of the leech. J. Physiol. (Lond.) 209: 647-667.

Ort, C. A., W. B. Kristan, Jr., and G. S. Stent (1974) Neuronal control of swimming in the medicinal leech. II. Identification and connections of motor neurons. J. Comp. Physiol. 94: 121-156.

Poon, M. (1976) A neuronal network generating the swimming rhythm of the leech. Doctoral dissertation, University of California, Berkeley.

Poon, M., W. O. Friesen, and G. S. Stent (1978) Neuronal control of swimming in the medicinal leech. V. Connections between the oscillatory interneurones and the motor neurones. J. Exp. Biol. 75: 45-63.

Shafer, M. R., and R. L. Calabrese (1981) Similarities and differences in the structure of segmentally homologous neurons that control the hearts in the leech, Hirudo medicinalis. Cell Tissue Res. 214: 137-153.

Stewart, W. W. (1978) Functional connections between cells as revealed by dye-coupling with a highly fluorescent naphthalimide tracer. Cell 14: 741-759.

Stuart, A. E. (1970) Physiological and morphological properties 
of motoneurones in the central nervous system of the leech. J. Physiol. (Lond.) 209: 627-646.

Thompson, W. J., and G. S. Stent (1976) Neuronal control of heartbeat in the medicinal leech. II. Intersegmental coordination of heart motor neuron activity by heart interneurons. J. Comp. Physiol. 111: 281-307.

Weeks, J. C. (1980) The roles of identified interneurons in initiating and generating the swimming motor pattern of leeches. Doctoral dissertation, University of California, San Diego, La Jolla, CA.

Weeks, J. C. (1981) Neuronal basis of leech swimming: Separation of swim initiation, pattern generation, and intersegmental coordination by selective lesions. J. Neurophysiol. 45: 698-723.

Weeks, J. C. (1982a) Synaptic basis of swim initiation in the leech. I. Connections of a swim-initiating neuron (cell 204) with motor neurons and pattern-generating "oscillator" neurons. J. Comp. Physiol., in press.

Weeks, J. C. (1982b) Synaptic basis of swim initiation in the leech. II. A pattern generating neuron (cell 208) which mediates motor effects of swim-initiating neurons. J. Comp. Physiol., in press.

Weeks, J. C., and W. B. Kristan, Jr. (1978) Initiation, maintenance and modulation of swimming in the medicinal leech by the activity of a single neurone. J. Exp. Biol. 77: 71-88.

Weisblat, D. A., G. Harper, G. S. Stent, and R. T. Sawyer (1980) Embryonic cell lineages in the nervous system of the leech Helobdella triserialis. Dev. Biol. 76: 58-78.

Zipser, B. (1979) Identifiable neurons controlling penile eversion in the leech. J. Neurophysiol. 42: 455-464. 